The number of resicles may be judged by the fact that I counted forty-seven on the right hand alone. The toes were quite free, but there were two or three scattered vesicles over the metatarsals on either side. The rest of the body was free. There was no glandular enlargement and no abnormal physical sign to be discovered in any organ. The urine was normal. The patient was given a mixture containing perchloride of iron, sulphate of quinine, and chlorate of potash, the mouth ordered to be frequently washed out with dilnte Condy's fluid, the eyes to be bathed with boric acid solution, and some yellow oxide of mercury ointment to be smeared along the lid margins. He was ordered plenty of fluid nourishment, with two glasses of port daily. On the morning of the 24th he presented a most striking clinical picture, plunged in sleep so profound that he was with difficulty aroused, the lips swollen and pouting, saliva constantly dribbling from the mouth, and muco-pus exuding from the eyelids. He, however, took nourishment freely on being awakened, but immediately relapsed into deep sleep. The morning temperature was $102.6^{\circ}$ and the pulse 56 per minute. He was ordered a purge and the local treatment to be continued energetically. Three capillary tubes were filled from some of the vesicles on the hands and forwarded to the Clinical Research Association for bacteriological investigation. (Their report is addei.) On the 25th drowsiness was still marked, two or three of the vesicles on the fingers had become hæmorrhagic; the bowels had acted well and the breath was less offensive. The morning temperature was $102^{\circ}$ and the pulse 55 . On the 26 th there was slight improvement generally, the tongue tending to clean; the appetite was returning, and the boy began to take some interest in his surroundings. The morning temperature was $100^{\circ}$ and the pulse 55 . On the 27th there was marked improvement, the lips were showing healthy granulations, and the tongue was clean, showing islets of intact epithelium standing out on a raw background. The vesicles on the hands, where situated beneath thin skin, were becoming opaque, and where beneath thick skin were drying. The morning temperature was $99^{\circ}$ and the pulse was still only 54 per minute. On the 28 th the lad was quite bright; the lips and tongue were healing; slobbering only took place during sleep; the vesicles on the hands were drying up without suppuration, and the eyes were nearly well. The temperature was $99^{\circ}$ and the pulse 52. Convalescence was now rapid, and in a few days he was quite well, the slow pulse being almost the last symptom to disappear. The diagnosis presented no difficulties; if one makes a list of the various diseases characterised by vesicles we should have variola, varicella, vaccinia rash, syphilis, herpetic fever, foot-and-mouth disease, eczema, herpes, erythema bullosum, pemphigus, cheiropompholyx, scabies, traumatism, and hand-and-mouth disease of Hutchinson. From amongst these, foot and mouth disease is picked out by the distribution and character of the rash, its life history, the association of hand and mouth, the absence of prodromal fever, a history of previous varicella, and, finally and conclusively, by the results of the bacteriological investigation. The source of infection remains a mystery. The cows on the estate on which the boy's father lives and those belonging to the dairy from which the family's milk supply is obtained were alike free from disease, and no sheep, pigs, or donkeys in the neighbourhood were, as far as I could ascertain, affected, nor had the boy been employed in looking after any such animals.

[The following is the report of the Clinical Research Association :-

"Microscopic examination of the serum in the three tubes submitted to us after appropriate staining gave the following results. In two of the tubes the serum contained cocci, arranged in pairs and as staphylococci, but with some few streptococci. In the third, however, the streptococci preponderated. These organisms were isolated by means of plate cultivations. when the staphylococcus was found to present no plate cultivations. When the staphylococcus was found to present
marked differences from the staphylococcus epidermidis albus described by Welch as being a common inhabitant of the skin. The streptococcus presented the following characteristics. The organism grew well, though rather slowly, on all nutrient media except potato grew well, though rather lowly, on all nutrient the growth was extremely scanty). The growth in streak cultures consisted of minute, transparent, jelly-like, spherical colonies, not confluent, and not making their appearance until forty-eight to sixty hours after inoculation. Microscopically, it occurred in long, wavy chains of from thirty to fifty members, the individual cocei being grouped in pairs and somewhat smaller than the ordinary streptococcus erysipelatosis. It stained well with the aniline dyes and was not decolourised by Gram. From a consirleration of these points we have no doubt that we are dealing with the particular pathogenic streptococcus Klein descrilied as being the cause of the funt-and-mouth disease among cattle, \&c.-Crras. H. WeLLS, Seerctary."

Caterharn Valley.

\section{NOTES ON A CASE OF \\ HEMOPTYSIS AS A COMPLICATION OF TYPHOID FEVER; RECURRENCE AND DEATH.}

By A. G. M. CREAGH, M.R.C.S. Eng, L.S.A., MEIICAL OFELCER, CAPE COPPER CONPANY, LIMITED,

THE occurrence of severe and fatal hæmorrhages from the lungs in a non-phthisical patient during the course of typhoid fever is apparently a rare complication, no mention of it being found in the last edition of "Quain's Dictionary of Melicine" or in the works of Hilton Fagge, Burney leo, or Bristowe. The notes of the following case may therefore be of interest as occurring in the course of a disease so widespread as enteric fever.

The patient was a man aged thirty five years, healthy and well developed, who had had no serious illness with the exception of an attack supposed to have been rheumatic fevcr, contracted in Norway. There was no evidence of cardiac enfeeblement or abnormality. He was first seen on Sept. 15th at 1.30 P.M., with a temperature of $102 \cdot 3^{\circ} \mathrm{F}$., accompauied by shivering and malaise. On Sept. 16th and 17th the temperature ranged between $101.5^{\circ}$ and $102.2^{\circ}$. On the 18th the temperature at 10 A.M. was $101.2^{\circ}$, and at 8.30 P.Ir. $101 \cdot 8^{\circ}$. A slight amount of bronchitis in both chest fronts was present, and inspiratory and expiratory sounds were loud and rough. On the 19th, 20th, and 21 st the evening temperature reached $103.8^{\circ}$, falling in the mornings from half to three-quarters of a degree. The pulse ranged from 112 to 120 , and the respiration was 24 . There was no increase of vocal resonance, dulness, or bronchial breathing in any region, but a limited expectoration of a glairy, sticky nature, occasionally slighily tinged with blood. There was a thick mucoid accumulation in the nostrils, which was removed by the patient's efforts with great difficulty, and which at times consisted of blood clots, arising from a congested state of the mucous membrane. On the 21st there were gurgling and tenderness in the right iliac fossa, followed by gradually increasing abdominal distension. On the 24th (the tenth day of the illness) rose.coloured spots appeared on the abdomen, and considerable meteorism was present. The evening temperature was $1038^{\circ}$. On the 25 th the morning temperature fell to $101 \cdot 2^{\circ}$, rising in the evening to $1024^{\circ}$. At $2 \mathrm{~A} . \mathrm{M}$. on the morning of the 26 th the first attack of hromoptysis occurred, consisting of about two ounces of bright aerated blood. A second attack took place at 5 A.M., and a third and more severe hæmorrhage at 8 A.M., when the temperature fell to $98.4^{\circ}$ and the patient became cyanosed, with respiration 38 per minute and the pulse 120 and feeble. The seat of himorrhage appeared to be chiefly in the right front, gurgling in the bronchi being heard over a large area of the right lung and less so over the left. The hæmorrhages were checked by turpentine, ergot, sulphate of alum, and dilute sulphuric acid. The patient's condition was most critical, and at $\mathrm{my}$ request he was seen in consultation by two neighbouring practitioners. Ice was given freely by the mouth, digitalis was added to the medicine, the usual routine treatment of hæmoptysis was pursued, and the administration of turpentine and digitalis continued every four hours. During the day the patient rallied, his temperature rising to $101.2^{\circ}$ at 9 P.M. and the pulse slowing to 98 . The respiration was 28 . At 115 A.M. on the 27 th I was called and found that a fourth attack of hæmoptysis had set in with increasing dyspnœa: not more than one ounce and a half of blood were expectorated. The remedies previously successful were again administered and a hypodermic injection of ergotin was given but without effect, and the patient, choked by the bleeding, died at 2.15 A.M. The treatment throughout the case was by Dr. Burney Yeo's mixture, with the addition of small doses of wine of ipecacuanha. Two scruples of salol in powder were given in twenty-four hours, together with a diaphoretic cough mixture, during the early part of the illness when the bronchitic symptoms were most troublesome.

Remarks.-Although epistaxis is so common a symptom in typhoid ferer, hæmoptysis appears to be very rare. Doubtless they both depend upon the lessened coagulable power of the blood in this disease, and in forming one's prognosis it is well to bear in mind the possibility of such an occurrence amongst the many other complications to be feared. The 
above case was neither phthisical nor a hamophiliac. There is strong evidence to prove that the disease was conveyed through the milk-supply coming from an infected house where there were four cases of typhoid fever. The milk was not boiled before use, and a second inmate of the patient's house also contracted enteric fever. Some others to whom the milk had been supplied were protected by previous attacks; in other cases the milk was regularly boiled. In these latter no bad results have appeared as yet, a point in favour of the advisability of boiling milk.

Ookiep, Cape Colony.

\section{THE MORTALITY FROM EMPYEMA IN CHILDHOOD.}

BY J. P. WIGHTMAN, M.R.C.S. ENG., L.R.C.P. LOND.,

IATE SENIOR HOUSE SURGEON, INFIRMARY FOR CHILDREN, LIVERPOOL.

IN this condition, a serious and not uncommon one, a favourable prognosis may be given, providing that the diagnosis is made in the early stages. What can be more sad than a mother bringing her child, worn out by prolonged hectic due to a discharging empyema, for advice? The rapidity of convalescence, averaging from six to eight weeks, and the usual cure, no trace of the disease remaining, add a special attraction to a condition which, if left alone, must almost always produce a fatal result. The subject of this disease and its treatment has been brought forward in the various medical journals, this paper being in part a résumé of the various views and methods of treatment.

Signs of a recent attack of scarlet fever (desquamation \&c.) are by no means uncommon in patients seeking relief at a children's hospital. With regard to this, it is remarkable that among 1008 cases of scarlet fever, mostly in children, recorded in 'l'HE LANCET during the year 1891 empyema is not even mentioned as a complication; nor is this the case in a paper on Scarlet Fever published in Vol. XXI. of the St. Thomas's Hospital Reports. This naturally leads one to infer that empyema is most likely to occur if a case of scarlet fever is neglected. Various statistics of mortality are on record. The younger the patient the greater the risk of a fatal termination. The sooner the purulent effusion is removed the quicker the recovery. Rupture of an empyema through the chest wall or into the lung is a grave complication, though the latter occasionally leads to spontaneous cure. Apart from the above, danger to life is chiefly threatened by the onset of complications-viz.: (1) pericarditis (among 29 fatal cases ai the Liverpool Children's Infirmary ${ }^{1}$ pericarditis occurred 12 times, in 10 it was of the suppurative form); (2) peritonitis; and (3) septicæmia.

As regards the effect that different methods of treatment have, taken as a whole, I do not think resection of rib renders the chance of cure either greater or less, except in certain cases. At the Hospital for Sick Children, Great Ormondstreet, from 1880 to 1892 , 214 cases were treated. Of these, 85 were treated during the earlier period by incision, with 16 deaths, and 129 afterwards by resection of rib, with 23 deaths, the mortality, as will be seen, being nearly the same in each case. ${ }^{2}$ Mr. Godlee published in 1886 the result of 36 cases. The majority (19) were treated by resection, the remainder by incision or aspiration. Of these cases only 1 was fatal. In THE LANCET of May 5th, 1894, I published the results of 118 cases, classifying all treatments together, with 23 deaths. In the same journal ${ }^{3}$ Dr. F. E. Batten of London published the results at the Hospital for Sick Children, Great Ormond-street, for the year 1893-94. Of 43 cases treated by resection, 5 were fatal. In THE LANCET also he asserts strongly that resection is the only treatment for empyema, a statement which I think cannot be accepted without much reserve. Dr. E. Cautley of London, at a meeting of the London Medical Society, ${ }^{4}$ in a paper based upon a series of 86 cases treated by various methods, gave a mortality of 16.6 per cent. The rate of mortality was the same after resection as after incision, with the exception that 5 out of 6 cases under two years old, treated by resection, were fatal. His opinion was

1 The Lancer, May 5th, 1894.
2 Mr. Bernard Pitts : The LANCET, Sept. 9th, 16th, 23rd, and 30th, and 0ct. 14th, 1893

3 THE Laycer', June 2nd, 1894.

4 Tere Lancet, Feb. 2nd, 1895. that resection ought only to be had recourse to in cases in which the tube could not be inserted without, when drainage was imperfect, or for the cure of an old sinus. Dr. Morison of Hartlepool (34 cases, 2 deaths) upholds incision. ${ }^{5}$ By the courtesy of Mr. Jordan Lloyd of Birmingham I am able to publish the treatment and results at the Birmingham and Midland Children's Hospital for the last five years. The total number of cases treated was 123 ; of these, 99 were cured, 20 were fatal, and of 4 there are no records. Among children of three years of age and under there were 43 cases; of these, 18 ended fatally. In the 99 cases cured the average stay in hospital was seven weeks and a half, the shortest stay eleven days, and the longest 164 days. Resection of rib was performed in 6 cases. I am indebted to $\mathrm{Mr}$. $\mathrm{H}$. G. Davis, house surgeon of the hospital, for taking much trouble in the preparation of the hospital statistics.

The rontine treatment is incision and drainage as soon as pus is determined. Resection of rib is exceptional as a primary procedure.

If the above figures are put together they number 656 cases of empyema in children, with 104 deaths, giving a death-rate of 16 per cent.

The extreme gravity of empyema in a young child may be seen by the following :-

\section{Mortality from Empyema in Children three years old} and under.

Dr. Goodhart (Guy's Hospital Reports)... Cases. Deaths. .

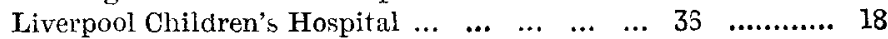

These figures give a death-rate of a little over 50 per cent. Rawdon, Leeds.

\section{a dittror} OF

\section{H O P I T A L P R A C T I C E, BRITISH AND FOREIGN.}

Nulla autem est alia pro certo noscendi via, nisi quamplurimas et morborum et dissectionum historias, tum aliorum tum proprias collectas habere, et inter se comparare.-MoRGAGNI De Sed. et Caus. Morb.. habere, et inter so

\section{ROYAL FREE HOSPITAL.}

CHRONIC RIGHT-SIDED THE SUPERIOR VENA CAVA SMUTATING INTRA-THORACIC TUMOUR; REMARKS.

(Under the care of Dr. H. SAlnsBURY.)

THE symptoms to which malignant growths of the chest give rise are very variable, depending upon the starting-point of the disease, whether pleura, bronchial tubes, or lung tissue. As these symptoms may be for a long time only those of a simple inflammation of the part attacked, this difficulty in diagnosis will be readily appreciated. The results which inflammation in its several stages and manifold incidence may bring about constitute an almost infinite variety of combinations. Here is an instance in which the diagnosis of intra-thoracic tumour, probably new growth, was made with some confidence, and yet the result of the post-mortem examination proved this to have been a mistake. The changes produced by the inflammation were unusual and extensive, but they were in no way the result of tumour formation.

A woman aged sixty-two was admitted into the Royal Free Hospital on Nov. 22nd, 1894, suffering from dyspnoea (of the variety orthopnœa), with much cyanosis and cough. She stated that she had suffered from winter cough for some years, that her present cough had been worse since the taking of a chill some six weeks before admission, and that her breath had become very short, especially of late. Two weeks before entering the hospital she said that she had noticed some blood mixed with the expectoration. Since the chill-i.e., during a period of six weeks-she was conscious of having wasted and lost strength. On examination the evidence of fluid in the right pleura was found but though the chest on the right side was dull and 